\title{
Papers
}

\section{Incidence of cancer among Nordic airline pilots over five decades: occupational cohort study}

\author{
Eero Pukkala, Rafael Aspholm, Anssi Auvinen, Harald Eliasch, Maryanne Gundestrup, \\ Tor Haldorsen, Niklas Hammar, Jón Hrafnkelsson, Pentti Kyyrönen, Anette Linnersjö, \\ Vilhjálmur Rafnsson, Hans Storm, Ulf Tveten
}

\begin{abstract}
Objective To assess the incidence of cancer among male airline pilots in the Nordic countries, with special reference to risk related to cosmic radiation. Design Retrospective cohort study, with follow up of cancer incidence through the national cancer registries.

Setting Denmark, Finland, Iceland, Norway, and Sweden.

Participants 10032 male airline pilots, with an average follow up of 17 years.

Main outcome measures Standardised incidence ratios, with expected numbers based on national cancer incidence rates; dose-response analysis using Poisson regression.

Results 466 cases of cancer were diagnosed compared with 456 expected. The only significantly increased standardised incidence ratios were for skin cancer: melanoma 2.3 (95\% confidence interval 1.7 to 3.0), non-melanoma 2.1 (1.7 to 2.8), basal cell carcinoma 2.5 (1.9 to 3.2 ). The relative risk of skin cancers increased with the estimated radiation dose. The relative risk of prostate cancer increased with increasing number of flight hours in long distance aircraft.

Conclusions This study does not indicate a marked increase in cancer risk attributable to cosmic radiation, although some influence of cosmic radiation on skin cancer cannot be entirely excluded. The suggestion of an association between number of long distance flights (possibly related to circadian hormonal disturbances) and prostate cancer needs to be confirmed.
\end{abstract}

\section{Introduction}

Airline pilots are occupationally exposed to ionising radiation, with doses of 2-6 mSv per year compared with an annual dose from background gamma radiation of approximately $1 \mathrm{mSv}$. Cosmic radiation at the common cruising altitudes consists mainly of gamma and neutron radiation. In 1990 the International Commission on Radiological Protection recommended that in-flight exposure of jet aircrew to natural radiation should be regarded as an occupa- tional exposure. ${ }^{1}$ Flight personnel may also be exposed to electromagnetic fields from cockpit instruments, jet fuel, and substances emanating from materials used in aircraft construction. In addition, it has been suggested that disruptions in sleep-wake cycles associated with flying across time zones may increase the risk of cancer by suppressing secretion of melatonin ${ }^{2}$ or by some other hormone related mechanism.

The aim of this paper is to describe cancer incidence among male commercial airline pilots from all five Nordic countries. The presentation of the results and discussion about possible causes will focus on skin cancer and cancers hypothesised in advance to have an association with cosmic radiation.

\section{Methods}

We identified national cohorts of airline pilots from various registers in the Nordic countries. In Denmark we enrolled all members of commercial cockpit crew on file since 1946 in the National Clinic of Aviation Medicine, University Hospital, Copenhagen (3790 men). ${ }^{3}$ In Finland we included all 793 male pilots who had been flying for Finnair or its subsidiaries up to 1996. In Iceland the cohort consisted of 239 men who, according to computerised files of the Icelandic Aviation Authority, were licensed commercial pilots. ${ }^{4}$ In Norway the cohort included all 3752 male commercial pilots who had a valid licence between January 1946 and February 1994. ${ }^{5}$ The Swedish cohort consisted of 1478 male aircraft pilots of the Scandinavian Airline System (SAS) resident in Sweden, who were employed between 1957 and $1994{ }^{6}$

We linked the cohorts to the national population registers and obtained the correct personal identifier and the possible dates of emigration, immigration, or death for every cohort member. We followed up the cohort for incident cancer cases through record linkage with the national countrywide cancer registries existing in all Nordic countries. The ethical committee of Karolinska Institute (Sweden) and the scientific committee of Copenhagen and Fredriksberg Communes (Denmark) approved the study. The national cancer registries also have an internal evaluation procedure whereby ethically unacceptable studies do not get permission to use the data.

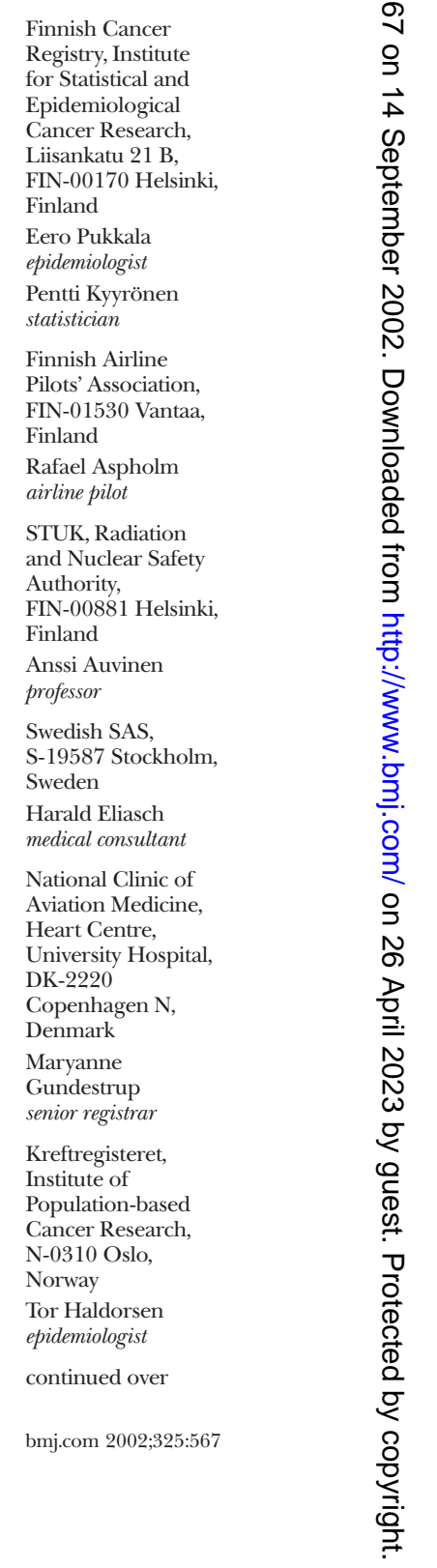


Institute of

Environmental

Medicine,

Karolinska Institute,

S-17177 Stockholm,

Sweden

Niklas Hammar

epidemiologist

Department of

Epidemiology,

Stockholm Centre

of Public Health,

S-17176 Stockholm,

Sweden

Anette Linnersjö

statistician

Department of Oncology,

Landspitalinn,

ICE-105 Reykjavik,

Iceland

Jón Hrafnkelsson

medical doctor

Department of

Preventive

Medicine,

University of

Iceland, ICE-105

Reykjavik, Iceland

Vilhjálmur

Rafnsson

professor

Cancer Prevention

and

Documentation,

Danish Cancer

Society, DK-2100

Copenhagen $\varnothing$,

Denmark

Hans Storm

medical doctor

Institute for Energy Technology, N-2007

Kjeller, Norway

Ulf Tveten

senior scientist

Correspondence to:

E Pukkala

eero.pukkala@

cancer.fi
Follow up for cancer for each participant started at the date of first employment, at immigration, or on the date of the start of cancer registration, whichever was latest, and ended at emigration, at death, or on a common closing date (the date until which cancer registration is complete), whichever was first. The cancer follow up period was 1943 to 1996 in Denmark, 1953 to 1997 in Finland, 1984 to 1997 in Iceland, 1962 to 1996 in Norway, and 1961 to 1996 in Sweden. In evaluating exposure to radiation, we also took into account the flight histories of the pilots from the years before the period of follow up for cancer.

We collected the numbers of block hours (that is, time from departure gate to arrival gate) in different types of flights from the seniority lists and other documents on flight histories. An expert panel classified the aircraft into low altitude, intermediate distance, and long distance categories, similarly in all countries. To quantify the radiation exposure, we converted the aircraft specific block hours to effective doses (mSv), on the basis of a Norwegian estimation of average radiation in different types of aircraft. ${ }^{7}$

We counted the numbers of observed cases of cancer and person years at risk by five year age groups and five year calendar periods. We calculated the expected numbers of cases for total cancer and for specific types of cancer by multiplying the number of person years in each stratum by the corresponding national cancer incidence rate.

To calculate the standardised incidence ratios, we divided the observed numbers of cases by the corresponding expected numbers. We defined the exact $95 \%$ confidence interval for each ratio on the assumption that the number of observed cases followed a Poisson distribution. We used Poisson regression to adjust for the effects of calendar period and broad age categories $(<60, \geqslant 60)$, to assess possible interactions between the factors, and to estimate the statistical significance of the $(\log )$ linear trends.

\section{Results}

The cohort consisted of 10032 men under follow up, amounting to 177244 person years (table 1). The mean length of follow up was thus 17 years. Almost $30 \%$ of the person years were in the category of at least 20 years' follow up since the time of first employment.

During the follow up, 466 cases of cancer were diagnosed compared with 456 expected, giving a standardised incidence ratio of 1.02 (table 2). The standardised incidence ratio was increased for various categories of skin cancer. The relative risk of skin melanoma increased significantly with increasing estimated exposure to radiation during flight; this trend was especially strong ( $\mathrm{P}$ for linear trend $=0.02$ ) for skin melanoma of the trunk among pilots with $>20$ $\mathrm{mSv}$ exposure (table 3). Some indication of increasing risk with increasing radiation dose existed for other types of skin cancer and overall cancer but not for any subcategory of leukaemia or any other cancer site (table 3).

\section{Multivariate analysis}

In the Poisson regression analysis the relative risk of skin melanoma increased with the cumulative dose $(\mathrm{P}$
Table 1 Number of person years at risk among male airline pilots

\begin{tabular}{lc} 
Variable & Person years (\%) \\
\hline Total sample & $177243(100)$ \\
\hline Country: & \\
\hline Denmark & $65086(37)$ \\
\hline Finland & $14600(8)$ \\
\hline Iceland & $2520(1)$ \\
\hline Norway & $65837(37)$ \\
\hline Sweden & $29200(16)$ \\
\hline Age (years): & $32897(19)$ \\
\hline$<30$ & $57297(32)$ \\
\hline $30-39$ & $45771(26)$ \\
\hline $40-49$ & $26886(15)$ \\
\hline $50-59$ & $11244(6)$ \\
\hline $60-69$ & $3151(2)$ \\
\hline$\geqslant 70$ & $33848(19)$ \\
\hline Block hours, long haul ${ }^{*}$ & $13673(8)$ \\
\hline $1-4999$ & $10922(6)$ \\
\hline $5000-99$ 999 & $82249(46)$ \\
\hline$\geqslant 10000$ & $26089(15)$ \\
\hline Estimated radiation dose $(\mu S v)^{*}:$ & $24201(14)$ \\
\hline $1-2999$ & $20004(11)$ \\
\hline $3000-9999$ &
\end{tabular}

*Do not add up to $100 \%$, because the category "no or unknown exposure" is excluded.

for linear trend=0.008) (table 4) and decreased towards more recent calendar periods. In comparison with the reference period 1994-7, the relative risks were 1.71 (95\% confidence interval 0.77 to 3.80 ) for the period $1943-82,1.62$ (0.72 to 3.64) for 1983-7, and $1.16(0.54$ to 2.49) for 1988-93.

The relative risk of prostate cancer in pilots aged over 60 increased with the number of block hours in long haul aircraft: eight cases occurred among pilots with more than 10000 block hours-relative risk 3.88 (1.26 to 11.9) in comparison with the category of $1-4999$ hours ( $\mathrm{P}$ for linear trend $=0.01$ ). We observed no increase in risk with the number of block hours in long haul aircraft in younger pilots, in whom hereditary factors are assumed to have a major role.

\section{Discussion}

We expected pilots to have a cancer pattern typical of high social classes ${ }^{8}$-for example, standardised incidence ratios of 1.2 for prostate cancer and 1.3 for acute myeloid leukaemia. We found ratios of 1.2 and 1.4 for these two cancers. The main exceptions upwards from the social class I pattern were various types of skin cancer. The standardised incidence ratio for skin melanoma in the highest social class varies from 1.1 in the head and neck region to 1.8 in the limbs, whereas the pilots had ratios of 2.3-2.5 across all subsites. Standardised incidence ratios of 1.5 for basal cell carcinoma and 1.1 for other non-melanoma skin cancer would be typical for social class I; we found ratios of 2.5 and 2.1. The lack of increased risk for cancers for which active case finding tends to increase incidence (such as cancers of the thyroid and prostate) suggests that regular medical surveillance is not likely to contribute to our findings. Two non-Nordic cohort studies of cancer mortality among male airline pilots ${ }^{10}{ }^{11}$ and two studies of both incidence and mortality ${ }^{12} 13$ showed excess mortality from skin melanoma (combined standard- 
ised mortality ratio $2.0,95 \%$ confidence interval 1.0 to 3.8 ) and brain cancer (1.5, 0.9 to 2.2$)$ and increased incidence of prostate cancer (standardised incidence ratio $1.7,1.2$ to 2.3$)$ and brain cancer $(1.7,0.9$ to 3.3$) .{ }^{14}$

\section{Cosmic radiation}

We based our estimates of dose of cosmic radiation on calculations for the Norwegian cohort, ${ }^{7}$ and we used the CARI software developed at the US Federal Aviation Authority. CARI is based on a combination of in-flight measurements and model based calculations. The results of CARI correlate with empirical measurements. Our calculations were performed for Norwegian airline pilots, but because flight distributions are comparable the dose estimates are also applicable to the other Nordic countries as semiquantitative estimates.

The effects of occupational exposure to ionising radiation on leukaemia risk have been studied primarily among cohorts of workers in the nuclear industry. A pooled analysis of seven cancer mortality studies in nuclear workers, with 2.1 million person years of follow up, showed an increased risk ratio of 1.22 for leukaemia excluding chronic lymphatic leukaemia for a cumulative protracted dose of $100 \mathrm{mSv}$ compared with zero dose.$^{15}$ In our cohort the estimated cumulative doses, however, exceeded $20 \mathrm{mSv}$ for only $11 \%$ of the follow up time (table 1), so the excess risk expected on the basis of the previous risk estimates would not exceed 1.05. We found only seven cases of non-chronic lymphatic leukaemia in pilots with a cumulative dose of $3 \mathrm{mSv}$ (4.2 expected), and no clear association with radiation dose existed.

\section{Skin cancer}

Consistent with our finding of an increased risk of skin cancers, the three Nordic studies on incidence of cancer among cabin crew published so far indicate a twofold to threefold excess risk of skin cancer. ${ }^{16-18}$ The major risk factors for malignant melanoma of the skin include intermittent sun exposure, sunburn at early
Table 2 Observed and expected numbers of cases of cancer and standardised incidence ratios among male airline pilots in the Nordic countries

\begin{tabular}{|c|c|c|c|}
\hline Primary site (ICD-7 code) & Observed & Expected & $\begin{array}{l}\text { Standardised incidence } \\
\text { ratio }(95 \% \mathrm{CI})\end{array}$ \\
\hline All sites $(140-208)^{*}$ & 466 & 455.6 & $1.02(0.93$ to 1.12$)$ \\
\hline Stomach (151) & 21 & 21.8 & $0.96(0.59$ to 1.47$)$ \\
\hline Colon (153) & 31 & 32.9 & $0.94(0.64$ to 1.34$)$ \\
\hline Rectum (154) & 19 & 22.4 & 0.85 (0.51 to 1.32$)$ \\
\hline Pancreas (157) & 12 & 13.0 & $0.92(0.48$ to 1.61$)$ \\
\hline Larynx (161) & 9 & 7.59 & $1.19(0.56$ to 2.29$)$ \\
\hline Lung (162) & 51 & 66.5 & 0.77 (0.57 to 1.01$)$ \\
\hline Prostate (177) & 64 & 52.9 & $1.21(0.93$ to 1.54$)$ \\
\hline Testis (178) & 21 & 18.9 & $1.11(0.69$ to 1.70$)$ \\
\hline Kidney (180) & 14 & 18.5 & 0.76 (0.41 to 1.27$)$ \\
\hline Bladder (181) & 29 & 33.8 & $0.86(0.57$ to 1.23$)$ \\
\hline Skin melanoma (190): & 56 & 24.4 & $2.29 \dagger$ (1.73 to 2.98$)$ \\
\hline Head and neck (190.0-4)‡ & 7 & 2.81 & $2.49 \dagger(1.00$ to 5.14$)$ \\
\hline Trunk (190.5)‡ & 32 & 13.7 & $2.33 \dagger(1.60$ to 3.30$)$ \\
\hline Limbs (190.6-7)‡ & 14 & 6.12 & $2.29 \dagger(1.25$ to 3.84$)$ \\
\hline Other skin $(191)^{\star}$ : & 27 & 13.0 & $2.08 \dagger(1.74$ to 2.79$)$ \\
\hline Kaposi's sarcomał & 0 & 0.29 & $0.00(0.00$ to 12.7$)$ \\
\hline Brain, nervous system (193) & 18 & 21.4 & $0.84(0.50$ to 1.33$)$ \\
\hline Thyroid (194) & 3 & 3.40 & 0.88 (0.18 to 2.58$)$ \\
\hline Bone (196) & 0 & 1.53 & $0.00(0.00$ to 2.41$)$ \\
\hline Soft tissue (197) & 3 & 3.33 & $0.90(0.19$ to 2.63$)$ \\
\hline Leukaemia (204-208): & 15 & 12.3 & $1.21(0.68$ to 2.00$)$ \\
\hline Chronic lymphatic $\neq$ & 4 & 3.88 & $1.03(0.28$ to 2.64$)$ \\
\hline Otherł: & 11 & 8.46 & $1.30(0.65$ to 2.33$)$ \\
\hline Acute myeloid $\ddagger$ & 6 & 4.27 & $1.41(0.52$ to 3.06$)$ \\
\hline \multicolumn{4}{|l|}{ Not included above } \\
\hline Basal cell carcinoma of the skin§ & 61 & 24.8 & $2.46 \dagger(1.88$ to 3.16$)$ \\
\hline
\end{tabular}

*Excludes basal cell carcinoma and, in Denmark, all non-melanoma skin cancers diagnosed before 1979 †Significant at $\mathrm{P}<0.05$

$\ddagger$ Subcategory also included in main category.

§Only Denmark (1979-96) and Finland (1953-97).

age, and host factors related to skin colour and naevi. ${ }^{19}$ Aircraft windows block ultraviolet radiation, and measurements of ultraviolet radiation reveal only minimal exposure in the cockpit at high cruise altitudes. ${ }^{20}$

We had two a priori approaches to separate the behavioural risk factors for skin melanoma from direct

Table 3 Observed and expected numbers of cases of cancer and standardised incidence ratios among male airline pilots in the Nordic countries, by cancer site and estimated cumulative dose during flights

\begin{tabular}{|c|c|c|c|c|c|c|c|c|c|c|c|c|c|}
\hline \multirow[b]{3}{*}{ Primary site } & \multicolumn{13}{|c|}{ Cumulative dose ( $\mu \mathrm{Sv})$} \\
\hline & \multicolumn{3}{|r|}{$1-2999$} & \multicolumn{3}{|c|}{$3000-9999$} & \multicolumn{3}{|c|}{$10000-19999$} & \multicolumn{3}{|r|}{$\geqslant 20000$} & \multirow{2}{*}{$\underset{\text { trend }}{\mathrm{P}}$} \\
\hline & Obs & Exp & SIR $(95 \%$ CI) & Obs & Exp & SIR $(95 \% \mathrm{Cl})$ & Obs & Exp & SIR (95\% CI) & Obs & $\operatorname{Exp}$ & SIR (95\% CI) & \\
\hline All sites* & 149 & 159.1 & 0.94 (0.79 to 1.10$)$ & 52 & 49.7 & 1.05 (0.78 to 1.37$)$ & 93 & 82.8 & $1.12(0.91$ to 1.38$)$ & 137 & 123.0 & 1.11 (0.94 to 1.32$)$ & 0.11 \\
\hline Lung & 19 & 20.7 & $0.92(0.55$ to 1.43$)$ & 4 & 6.6 & 0.61 (0.17 to 1.56$)$ & 9 & 11.8 & $0.76(0.35$ to 1.44$)$ & 15 & 21.2 & 0.71 (0.40 to 1.17$)$ & 0.48 \\
\hline Prostate & 15 & 17.1 & $0.88(0.49$ to 1.44$)$ & 5 & 4.9 & $1.03(0.33$ to 2.40$)$ & 13 & 10.7 & 1.21 (0.64 to 2.07) & 24 & 16.6 & 1.44 (0.93 to 2.15$)$ & 0.12 \\
\hline Skin melanoma: & 14 & 10.2 & 1.37 (0.75 to 2.30$)$ & 9 & 3.0 & $3.00 \dagger$ (1.37 to 5.69) & 13 & 4.3 & $3.02 \dagger(1.61$ to 5.17$)$ & 17 & 4.9 & $3.47 \dagger(2.02$ to 5.55$)$ & 0.008 \\
\hline Head and neckł & 3 & 1.2 & 2.53 (0.52 to 7.39$)$ & 2 & 0.3 & 5.81 (0.70 to 21.0$)$ & 0 & 0.5 & 0.00 (0.00 to 7.62$)$ & 2 & 0.6 & 3.49 (0.42 to 12.6$)$ & 0.95 \\
\hline Trunk $\ddagger$ & 9 & 5.8 & $1.56(0.71$ to 2.96$)$ & 3 & 1.7 & 1.81 (0.37 to 5.29) & 6 & 2.4 & 2.48 (0.91 to 5.39$)$ & 12 & 2.8 & $4.29 \dagger$ (2.21 to 7.49$)$ & 0.02 \\
\hline Limbsł & 1 & 2.6 & 0.39 (0.01 to 2.18) & 3 & 0.8 & 3.87 (0.80 to 11.3$)$ & 6 & 1.1 & $5.68 \dagger$ (2.09 to 12.4) & 3 & 1.2 & 2.57 (0.53 to 7.50$)$ & 0.04 \\
\hline Other skin* & 7 & 4.5 & 1.55 (0.62 to 3.20$)$ & 1 & 1.3 & 0.77 (0.02 to 4.31$)$ & 6 & 2.4 & 2.48 (0.91 to 5.40$)$ & 12 & 3.7 & $3.26 \dagger$ (1.68 to 5.69) & 0.08 \\
\hline Thyroid & 2 & 1.4 & $1.42(0.17$ to 5.14$)$ & 0 & 0.5 & $0.00(0.00$ to 7.84$)$ & 1 & 0.6 & $1.63(0.04$ to 9.10$)$ & 0 & 0.6 & 0.00 (0.00 to 5.77$)$ & 0.54 \\
\hline Leukaemia: & 3 & 4.4 & $0.69(0.14$ to 2.01$)$ & 3 & 1.5 & 1.99 (0.41 to 5.81$)$ & 4 & 2.2 & $1.85(0.50$ to 4.74$)$ & 4 & 3.0 & 1.35 (0.37 to 3.45$)$ & 0.37 \\
\hline Chronic lymphaticł & 0 & 1.1 & 0.00 (0.00 to 3.43$)$ & 1 & 0.4 & 2.46 (0.06 to 13.7) & 2 & 0.8 & 2.64 (0.32 to 9.52$)$ & 1 & 1.2 & 0.81 (0.02 to 4.51$)$ & 0.54 \\
\hline Otherł: & 3 & 3.3 & 0.91 (0.19 to 2.67) & 2 & 1.1 & $1.82(0.22$ to 6.56$)$ & 2 & 1.4 & $1.43(0.17$ to 5.16$)$ & 3 & 1.7 & $1.73(0.36$ to 5.04$)$ & 0.46 \\
\hline Acute myeloid $\neq$ & 1 & 1.7 & $0.60(0.02$ to 3.36$)$ & 1 & 0.5 & 1.93 (0.05 to 10.7$)$ & 1 & 0.7 & $1.41(0.04$ to 7.84$)$ & 2 & 0.9 & 2.12 (0.26 to 7.64$)$ & 0.98 \\
\hline \multicolumn{14}{|l|}{ Not included above } \\
\hline
\end{tabular}

Exp=expected; Obs=observed; $S I R=$ standardised incidence ratio

*Excludes basal cell carcinoma and, in Denmark, all non-melanoma skin cancers diagnosed before 1979

†Significant at $\mathrm{P}<0.05$.

† Subcategory also included in main category.

§Only Denmark (1979-96) and Finland (1953-97). 
Table 4 Observed numbers of selected cancers among male airline pilots in the Nordic countries and relative risk ( $95 \%$ confidence interval) estimates derived from Poisson regression model, by estimated cumulative dose. Adjusted for age and calendar period

\begin{tabular}{|c|c|c|c|c|c|c|c|c|c|c|}
\hline \multirow[b]{2}{*}{ Cumulative dose $(\mu \mathrm{Sv})$} & \multicolumn{2}{|r|}{ All sites* } & \multicolumn{2}{|c|}{ Skin melanoma } & \multicolumn{2}{|r|}{ Other skin* } & \multicolumn{2}{|c|}{ Basal cell carcinoma† } & \multicolumn{2}{|c|}{$\begin{array}{l}\text { Leukaemia, excluding } \\
\text { chronic lymphatic }\end{array}$} \\
\hline & No & Relative risk & No & Relative risk & No & Relative risk & No & Relative risk & No & Relative risk \\
\hline $1-2999$ & 149 & 1 (reference) & 14 & 1 (reference) & 7 & 1 (reference) & 7 & 1 (reference) & 3 & 1 (reference) \\
\hline $3000-9999$ & 52 & 1.12 (0.81 to 1.53$)$ & 9 & 2.10 (0.91 to 4.87$)$ & 1 & $0.52(0.06$ to 4.26$)$ & 6 & 1.83 (0.70 to 4.79$)$ & 2 & 1.90 (0.32 to 11.5$)$ \\
\hline $10000-19999$ & 93 & 1.19 (0.92 to 1.54$)$ & 13 & $2.20 \ddagger(1.03$ to 4.72$)$ & 6 & $1.50(0.50$ to 4.48$)$ & 8 & 1.42 (0.60 to 3.41$)$ & 2 & $1.42(0.23$ to 8.70$)$ \\
\hline$\geqslant 20000$ & 137 & 1.19 (0.93 to 1.51$)$ & 17 & $2.78 \ddagger(1.30$ to 5.93$)$ & 12 & $1.92(0.74$ to 4.98$)$ & 32 & 1.86 (0.98 to 3.54$)$ & 3 & $1.78(0.32$ to 10.0$)$ \\
\hline $\mathrm{P}$ trend & & 0.13 & & 0.007 & & 0.14 & & 0.17 & & 0.53 \\
\hline
\end{tabular}

${ }^{\star}$ Excludes basal cell carcinoma and, in Denmark, all non-melanoma skin cancers diagnosed before 1979. tOnly Denmark (1979-96) and Finland (1953-97)

occupational hazards such as cosmic radiation. Firstly, because the relative difference between pilots and other people in the frequency of travelling to the south is diminishing over time, we hypothesised that the standardised incidence ratio would decrease towards recent years if it is related to sunbathing. The relative risk for skin melanoma among pilots was clearly higher before the mid-1980s than in the 1990s, suggesting that sunbathing is a major determinant of risk. The second approach was to study the risk by skin area: the risk in the head and neck area is similar irrespective whether the person is regularly outdoors or not, whereas skin melanoma in the trunk and limbs is much more common among indoor workers. ${ }^{8}$ The risk among pilots was similarly increased for melanoma in the head and neck and for melanoma in the trunk and limbs, which according to our hypothesis might point to factors other than sunbathing.

In previous studies, skin melanoma has rarely been associated with ionising radiation. We conclude that although the relative risk of skin melanoma increased significantly with estimated dose of ionising radiation, the excess may well be attributable to ultraviolet radiation.

\section{Jet lag}

The causes of prostate cancer are poorly understood. Melatonin may have a protective effect, ${ }^{2}$ and disruptions to sleep-wake cycles may increase cancer risk by suppressing melatonin secretion. According to one hypothesis, melatonin would increase the risk of hormone related cancers, whereas other people believe that it would have a systemic antioxidant-like effect. According to this theory, flight personnel flying over many time zones might have an excess risk. The main hormone related cancer among men is prostate cancer. Among pilots in our study, the relative risk of prostate cancer increased with the number of long haul hours. We cannot fully exclude the possibility that jet lag would increase the risk of hormone related cancers.

\section{Conclusions}

Few areas outside the Nordic countries have a history of several decades of population based registration of cancer. The large joint cohort size and five independent country specific observations in this joint Nordic study reduce the possibility of chance findings, and carefully registered incidence data help to avoid artefacts possibly included in the mortality statistics. Because of the complete population registration systems in all Nordic countries and accurate computerised record linkage procedures, the standardised incidence ratio estimates in this study are not prone to

\section{What is already known on this topic}

Airline pilots are occupationally exposed to cosmic radiation and other potentially carcinogenic elements

In the studies published so far, dose-response patterns have not been characterised

\section{What this study adds}

No marked risk of cancer attributable to cosmic radiation is observed in airline pilots

A threefold excess of skin cancers is seen among pilots with longer careers, but the influence of recreational exposure to ultraviolet light cannot be quantified

A slight increase in risk of prostate cancer with increasing number of long haul flights suggests a need for more studies on the effects of circadian hormonal disturbances

bias attributable to incomplete follow up or failures in record linkages.

Because our cohort included most of the cockpit crew ever certified in the Nordic countries, this study can be considered to have maximum potential to study cancer incidence among pilots. We were able to assess cancer risk by level of exposure, take into account characteristics of cancer (for example, subtypes of leukaemia, tumour latency), and estimate independent effects of exposure, age, and time period of the diagnosis in a way that has not been meaningful in small national settings. Apart from skin cancers, male Nordic pilots seem to have a pattern of cancer typical of that of high social class men in the Nordic countries. Our study shows a need for detailed studies focusing on possible work related factors involved in the evidently raised risk of skin cancer and the suggestive dose-response patterns in prostate cancer.

Contributors: All the authors actively participated in design, planning of analysis, writing the paper, and agreeing about conclusions. EP coordinated the work and is the guarantor.

Funding: Nordic Cancer Union and the participating institutes.

Competing interests: RA has been employed by Finnair as an airline pilot since 1988 and has shares in Finnair. He is also an active member of the Finnish Pilots' Association and has been reimbursed by the association for attending medical symposiums and conducting scientific research. HE has worked as an medical consultant for Scandinavian Airlines. The other authors have no connections to airline companies. 
11990 Recommendations of the International Commission on Radiological Protection. Annals of the ICRP 1991;21(1-3). (ICRP Publication 60.)

2 Stevens R, Davis S. The melatonin hypothesis: electric power and breas cancer. Environ Health Perspect 1996;104(suppl 1):135-40.

3 Gundestrup M, Storm HH. Radiation-induced acute myeloid leukaemia and other cancers in commercial jet cockpit crew: a population-based cohort study. Lancet 1999;354:2029-31.

4 Rafnsson V, Hrafnkelsson J, Tulinius H. Incidence of cancer among commercial airline pilots. Occup Environ Med 2000;57:175-9.

5 Haldorsen T, Reitan JB, Tveten U. Cancer incidence among Norwegian airline pilots. Scand J Work Environ Health 2000;26:106-11

6 Hammar N, Linnersjö A, Alfredsson L, Dammström B-G, Johansson M, Eliasch $\mathrm{H}$. Cancer incidence in airline and military aircraft pilots in Sweden 1961-1996. Aviat Space Environ Med 2002;73:2-7.

7 Tveten U, Haldorsen T, Reitan J. Cosmic radiation and airline pilots: exposure pattern as a function of aircraft type. Radiat Prot Dosim 2000;87:157-65

8 Pukkala E. Cancer risk by social class and occupation: a survey of 109,000 cancer cases among Finns of working age. In: Contributions to epidemiolog and biostatistics. Vol 7. Basel: Karger, 1995.

9 Andersen A, Barlow L, Engeland A, Kjærheim K, Lynge E, Pukkala E Work-related cancer in the Nordic countries. Scand J Work Environ Health 1999;25(suppl 2).

10 Kaji M, Tango T, Asukata I, Tajima N, Yamamoto K, Yamamoto Y, et al. Mortality experience of cockpit crewmembers from Japan Airlines. Avia Space Environ Med 1993;64:748-50.

11 Irvine D, Davies D. British Airways flightdeck mortality study, 1950-1992. Aviat Space Environ Med 1999;70:548-55.
12 Band P, Spinelli J, No VTY, Moody J, Gallagher RP. Mortality and cancer incidence in a cohort of commercial airline pilots. Aviat Space Environ Med 1990;61:299-302.

13 Band P, Nhu Le ND, Fang R, Deschamps M, Coldman AJ, Gallagher RP, et al. Cohort study of Air Canada pilots: mortality, cancer incidence, and leukemia risk. Am J Epidemiol 1996;143:137-43.

14 Ballard T, Lagorio S, De Angelis G, Verdecchia A. Cancer incidence and mortality among flight personnel: a meta-analysis. Aviat Space Environ Med 2000;71:216-24.

15 Cardis E, Gilbert ES, Carpenter L, Howe G, Kato I, Armstrong BK, et al. Effects of low doses and low dose rates of external radiation: cancer mortality among nuclear industry workers in three countries. Radiat Res $1995 ; 142: 117-32$

16 Pukkala E, Auvinen A, Wahlberg G. Incidence of cancer among Finnish airline cabin attendants, 1967-92. BMJ 1995;311:649-52

17 Haldorsen T, Reitan JB, Tveten U. Cancer incidence among Norwegian airline cabin attendants. Int J Epidemiol 2001;30:825-30.

18 Rafnsson V, Tulinius H, Jónasson JG, Hrafnkelsson J. Risk of breast cancer in female flight attendants: a population-based study (Iceland). Cancer Causes Control 2001;12:95-101.

19 Armstrong B, English DR. Cutaneous malignant melanoma. In Schottenfeld D, Fraumeni JF Jr, eds. Cancer epidemiology and prevention. 2nd ed. New York: Oxford University Press, 1996:1282-312.

20 Diffey B, Roscoe A. Exposure to solar ultraviolet radiation in flight. Avia Space Environ Med 1990;61:1032-5.

(Accepted 23 April 2002) 